Vedecký príspevok/ Scientific Article

Recenzované/ Review: 04. 05. 2021

https://doi.org/10.24040/eas.2021.22.1.55-76

\title{
The Current Challenges of Applied Social Science Research of Radon Spas' English Language Marketing Activities on the Internet: Selected Desk Research Results
}

Aktuálne výzvy aplikovaného spoločenskovedného výskumu aktivít internetového marketingu radónových kúpel'ov v anglickom jazyku: vybrané výsledky sekundárneho výskumu

\section{Peter Mihók}

Abstract: This paper summarises the challenges for applied social science research of radon spas' English language marketing activities on the internet. Our desk research results suggest that, in contrast with at least nine German and three Austrian radon spas (members of the European association of radon spas EURADON) the number of radon spas in the rest of the EU may be lower. Because we limited our research to spas whose internet webpages containing an English language sections, we have identified only seven such radon spas. We have found very significant differences with regard to size and form in which medical radon therapy has been advertised and explained in the English language at these websites. A combination of theoretical challenges, a lack of relevant English language academic publications in a field of Social Sciences and Humanities (SSH) and some specific research accreditation related to national laws contribute to the challenges in SSH research discussed in this paper.

Key words: Spas. Radon medical therapy. Health tourism. Medical tourism. Social Sciences and Humanities (SSH).

JEL Classification: Z33. H83.

\section{Introduction}

According to some academic authors, radon medical treatment "can be traced back to the medieval ages" (Lettner et al., 2017), when radon "was only indirectly known to have positive health effects a millennia ago" (Becker, 2004). However, as an inert radioactive gas, naturally occurring as a decaying product of radium, radon was discovered only in 1900. 
According to Zdrojewicz and Strzelczyk (2006), "in spite of long traditions, treatments utilizing radon-rich air or water have not been unequivocally embraced by modern medicine". Because opinions about radon medical treatment at spas "ranged from very enthusiastic to extremely critical", and at the same time "a number of factors influenced public opinion", the so called 'radon spa controversy' became a subject of academic research under medical sciences (Ibid.). Despite these controversies, several spas in Europe located near radon rich springs have been providing radon medical treatment for decades. While eligible for reimbursement by public medical insurance companies in some EU member states, radon medical therapy remained "a non-sanctioned treatment eagerly sought by certain patients, but scorned or dismissed by many physicians", especially in the United States of America (USA) (Erickson, 2007b).

This article is the first publication of UMB related to the research of the so called 'radon spa controversy' within the research project acronymed RadoNorm (referred in the Acknowledgment section). It concerns English language internet marketing activities of radon medical treatment services by spas located in the EU, but outside of Austria and Germany (note: the reasons of omitting these two states are dealt with in section 3). Moreover, this paper presents only those selected desk research results that have been found to be the most relevant in order for the UMB's RadoNorm team to prepare for the upcoming primary research activities in this project, which are planned in the autumn 2021, respectively spring and/or summer 2022 (as the so called 'Covid situation' and related travel restrictions would allow).

\section{Theoretical background}

Academic texts related to radon spas' often contain information falling at least partially under medical, natural and/or technical sciences. However, given existing limits in the research accreditation imposed on the Faculty of Economics of the UMB by related laws of the Slovak Republic, the UMB's preparatory desk research activities (whose selected results are summarised in this paper) have been limited only to the research activities falling under applied social science research (i.e. falling under SSH in full). From this reason, this section begins with a theoretical background related to boundaries between social sciences on the one hand; and medical, natural and/or technical sciences on the other. The remaining parts of this section deal with a relevant theoretical background falling under social sciences, in particular under economics and science tourism. 


\subsection{Cross disciplinarity, multidisciplinarity and interdisciplinarity in applied social science research focused on marketing in medical/health/wellness tourism}

Among the academic literature that we have reviewed, perhaps the most relevant theoretical background related to relationships between different research/science disciplines has been presented in the book of case studies on "Health and Social Science Interdisciplinary research" by Kessel, Rosenfield and Anderson (eds., 2008). According to the two of the three editors of this book, Kessel and Rosenfield, unidisciplinary framework have been found to be "no longer best equipped to address the complex problems facing global society", and therefore "interdisciplinary team science has emerged as the defining feature of the scientific endeavor in the twenty-first century".

According to the quoted authors, the term interdisciplinary research should refer to a true collaboration, i.e. a melding of disciplines, and not just the addition of techniques and technology from one field of research into another field. The quoted authors stressed that "interdisciplinary work implies that the various approaches are generally applied simultaneously over a substantial period of time rather than sequentially, which is more commonly termed multidisciplinary". They refer to "combinations of physiology and social sciences" as to an example of collaborations across major disciplinary boundaries, i.e. in order to differentiate it from interdisciplinary research (Ibid.).

Apart from formal and/or legal issues related to research accreditation of public universities/institutions, for ex. in 'post-socialist' EU member states, interdisciplinarity (as defined above) may pose additional practical challenges (see for ex.: Rhoten and Parker, 2004). According to Davis and Jovanovic (2021), specific challenges may exist in particular with regard to economics. The reason is that existing definitions of economics' boundaries with other sciences and within itself may be controversial, and moreover some of these definitions "have been used as a tool for justifying dominant views and dominant networks of researchers in economics".

With regard to a research of marketing activities of pro-profit entities, Lindgreen, Di Benedetto, Brodie and van der Borgh (2020) emphasized that apart from the economics, "general theories that provide insight into business relationships, systems, and markets have disciplinary foundations" also in psychology, sociology and management disciplines". Accordingly, "academic administrators should resist the temptation to push for crossdisciplinary research for its own sake, allowing cross-disciplinary bonds to form if deemed necessary for the research problem being undertaken". They also stressed that "explicit 
attention needs to be given to the process of theorizing, not theory, as an outcome". Instead of attempts to fit in completely into existing theoretical background, the quoted authors suggested that research projects involving inevitable cross-disciplinary research in applied social science should aim to "establish a clear vision for the research project, carefully construct a clear research question, work with senior colleagues who have access to mentors in different parts of the university, take advantage of institutes within your school that are problem-focused and are cross-disciplinary in nature, and develop a positioning strategy for your cross-disciplinary research that will interest the top academic journals" (Ibid.).

\subsection{Health tourism, medical tourism, spa tourism and wellness tourism}

In respect to the recommendation dealt with in the previous section, and also to the UMB Faculty of Economic's research accreditation and specialisation, we have attempted to summarise a relevant theoretical background for radon spas' marketing research activities under tourism sciences. This section summarizes the most relevant findings of this desk research activity.

Historical and cultural contexts of spa tourism have been a subject of many different academic publications, including very short articles as well as books with specific focuses under SSH (see for ex.: van Tubergen and van der Linden, 2002; Routh, Bhowmik, Parish and Witkowski, 1996; Large, 2015). The academic authors whose work we have studied have mostly agreed with the conclusion of van Tubergen and van der Linden (2002) that "throughout the ages the interest in the use of water in medicine has fluctuated from century to century and from nation to nation. The (medical) world has viewed it with different opinions, from very enthusiastic to extremely critical, and from beneficial to harmful". While the quote above relates to 'non-radon spas', Large (2015) provided an example of how radon spa therapies specifics have been briefly included into a historical review of spas culture, with a reference to the experiences of Sigmund Freud at the Austrian spa Gastein (the only spa referred in relation to radon medical therapy in this book). This implicit evidence, as well as some other evidence known to us, but not dealt with in this paper, suggests that radon spas played a rather very minor role, respectively very marginal role in a theoretical research of spas and spa tourism.

In a past, many differing definitions, especially definitions of the terms health tourism and medical tourism (as well as spa tourism and wellness tourism), have been published by academic authors active in tourism related sciences (see for ex.: Mueller and Kaufmann, 2000; Cook, 2008 or Kušen, 2011). According to Cook (2008), some of these definitions "appear to be influenced by the previously explored history of health tourism, which is largely based on 
resorts, spas and general wellness"; and understanding of tourism in these definitions "largely replicate the traditional understandings of mass tourism in sociology, where tourism is understood as a binary structure that operates as escapism from the everyday and routine, and with work and leisure distinguished" (Ibid.).

According to Kušen (2011), "many terms are used to describe the relationship between health and tourism in the framework of special tourism products such as health tourism, medical tourism, hospital/clinical tourism, wellness tourism, and sometimes travel medicine, often conceptually completely inconsistently". The quoted author explained that definitions of, resp. boundaries between medical and health tourism have been formulated "from the tourism point of view", despite that the practice are inevitably also linked to delimitations of competences between relevant national authorities in a field of tourism on the one side, and relevant health sector national authorities on the other side. He uses Croatia as an example to explain that, in this regard, many uncertainties still exist.

According to Ramos and Untong (2016), “there are no unanimous agreements regarding spa tourism among the definitions of terms such as health, wellbeing, medical, and wellness tourism. Taking into account the diverse discussions and controversies, one approach is to consider medical and wellness tourism as subdivisions of health tourism. For each of these notions, the main elements must be defined based on the characteristics and motivations of potential tourists. Health tourism includes all the health-related activities that fulfil the definition of tourism".

According to the International spa association (2021), "spas are places devoted to overall well-being through a variety of professional services that encourage the renewal of mind, body and spirit”. As Ramos and Untong (2016) explained in 'Encyclopedia of Tourism' (Jafari and Xiao (eds). 2016), the quoted "concept of spa has evolved from an initial definition of a location with natural thermal springs that help relieve or cure sickness to that of a place for physical, mental, and emotional alleviation primarily through water. Recently, spa therapy also involves alternative medical treatments and the use of the five senses to create a physical, mental, and emotional balance. Hence, spa therapy not only involves water, but also includes other forms of therapies such as massage or yoga that emphasizes relaxation and alleviation of the mind, body, and spirit". With regard to radon medical therapy implementation, this definition could be used in order to distinguish between radon spas and 'non-spa radon medical therapy facilities'.

As a particular types of spas, the International spa association defines 'medical spa' as "a facility that has a full-time licensed health care professional on-site, which is further defined as 
a health professional who has earned a degree of Doctor of Medicine" (International spa association 2021). With regard to radon spas, this definition can also be relevant

\subsection{Marketing in medical and health tourism}

According to a thorough review of academic papers dealing with 'the health tourism market' by Letunovska, Kwilinski and Kaminska (2020), it is "evident that the topics of marketing, consumption, and motivation are quite popular in the research of scientists from different countries". An important research finding relevant to a theoretical background relates to the fact that recent research of clients' motivation to consume services of medical and health tourism included "models of decision-making on the choice of health tourism services" (Ibid.).

Based on their reviewed content of academic studies, the quoted authors attempted to outline existing academic perceptions of relationships "between purely medical tourism, filled with medical supply, and another type of such tourism, namely preventive tourism, the purpose of which is to improve the health of tourists, but without targeted treatment of diseases" (Ibid.). Due to the limits of our capacities for this desk research activity, and also due to the maximum length allowed for this manuscript, we have been unable to summarise other theoretical background of medical, health and/or wellness tourism marketing activities which could be potentially relevant for research of radon spas' internet marketing activities. Given the above outlined focus on SSH, apart from a traditional theoretical background in marketing (for ex. Armstrong, Kotler, Trifts et al., 2017), books dealing with marketing in health and wellness tourism provide a relevant theoretical background (for ex. Peris-Ortiz and Álvarez-García (eds.), 2015), especially with regard to research of those internet marketing activities that concern health and wellness tourism (i.e. provision of services for which marketing typically involves, directly or indirectly, also client's economic satisfaction), i.e. not a provision of medical services (whose satisfaction related research falls at least partially under medical sciences).

\subsection{Radon therapy, radon spas and radon medical therapy at caves/mines/mofettes.}

The part of our desk research devoted to a search of a definition of the term 'radon [medical] therapy' in a literature relevant for medical/health tourism resulted in only one finding in the English language texts so far. According to Nagy, Kavasi, Kovacs and Somlai (2008), "radon therapy is defined as a medicinal therapy where [radon as] the active substance is known, however neither the dose for curative effect nor the duration of required treatment is identified". According to the same quoted authors, "radon therapy is a natural cure (usually 
supplemented with drug treatment) and most often occurs in spas, caves, and former underground mine areas" (Ibid.). (Note: outside of academic resources, we have identified a definition by a specialised medical spa focused agency, according to which "radon therapy is a type of medical treatment using naturally produced radon gas in specific quantities to relieve chronic pain and fatigue" (SpaDreams, 2021), which we have found relevant to present in this section in a form of a note).

A thorough search of academic databases, conducted within the RadoNorm project in late 2020 and early 2021, identified several academic papers that contained the term 'radon spa(s)'. However, none of these papers contained and referred to any definition of this term. The vast majority of the papers dealing, directly or indirectly, with the research of radon spas and/or other radon medical treatment tourist facilities, clearly felled under medical, technical and/or natural sciences (Tomkiv et al. 2021). Only three of these publications have been identified as falling under SSH, all written by Erickson (2007a, 2007b, 2007c), i.e. by just one author based in the USA, and moreover published in the same year. One of her publications contains also some data gathered during Ericson's trips to Europe, by means of which she visited "three [radon] spas, one radon steam bath, two curative tunnels, and one radon mine" (Erickson, 2007b).

Erickson (2007a, 2007b, 2007c) has not attempted to summarise, outline or implicitly suggest any theoretical framework relevant for this paper. Moreover, despite referring to a department of anthropology, the quoted author published the results relevant for our article in a journal about occurrence of dose-response relationships across a broad range of disciplines, including physiology, biochemistry, molecular biology, toxicology, radiation biology, pharmacology, pharmacology, medicine, experimental psychology, plant biology, as well as environmental and related sciences; i.e. in an interdisciplinary journal falling dominantly under medical and natural sciences, despite mentioning experimental psychology as an area falling partially under SSH.

Fleur, Azara and Michopoulou (2018) provide only one example of a paper identified in our desk research that provides theoretical background helpful for a potential implicit or 'negative' definition of radon spas. The reason is that the quoted authors' paper contains some theoretical background of "thermalism", i.e. use of bathing waters at various temperatures for medicinal- or health- related, as well as wellness- and leisure- related purposes. As the term 'thermalism' refers to heat, it may potentially differentiate from a use of bathing water at spas which is aimed at utilising any impact of radon's radioactive properties on human health. Independently to this, the paper by the quoted authors may potentially contain some theoretical 
background relevant for primary research of attitudes towards radon spas, because it provides an example of an ethnographic case study that explored residents' attitudes and perceptions towards spa development, by means of research falling fully under SSH.

Our desk research activity, whose results are dealt with in this paper, have not resulted in finding any academic text that would contain, quote or at least mention or refer to any text that could be used as a definition of the term 'radon spa(s)'. Nagy, Kavasi, Kovacs and Somlai (2008), the already quoted authors offers the only attempt to define 'radon medical therapy', do not deal with any spas related theory under tourism science or other scientific field relevant for this article.

Because this paper does not concern 'non-spa forms of radon medical therapy', we do not present the results of our desk research related to speleotherapy, i.e. the so called radon 'health mines', former mines, caves with high radon air concentration, and/or the so called 'mofettes' (note: the term 'mofette' is defined for ex. in the Merriam-Webster dictionary as "a vent from which carbon dioxide and some nitrogen and oxygen issue from the earth in a last stage of volcanic activity").

\section{Material and methods}

Apart from the quoted academic resources, the material used in our desk research (whose results are presented in this article) concerned English language texts used in the marketing of radon medical therapies in the internet pages of the seven different spas in the EU, all outside of Austria and Germany, which we have identified using the following described method (and which are listed in Table 1 in section 3.1). The omission of Austria and Germany, i.e. German language speaking EU members from the desk research activity dealt with in this article, resulted from an internal agreement within the RadoNorm project 'radon spas research team', because this team is composed of the researchers affiliated with the project partners from Austria, Belgium, the Czech Republic, Germany and Slovakia. Given that UMB and the Austrian project partner AGES are both equal co leaders of the 'radon spas related research tasks' in the RadoNorm project, and given also a rather high number of spas including radon medical therapies in Austria and Germany (dealt with in the following paragraph), the decision has been taken that a separate desk research activity concerning spas in Austria and Germany would be conducted by the Austrian and German RadoNorm project partners, i.e. in parallel to the research activity dealt with in this paper.

A need to identify relevant spas for the research dealt with in this article by means of our own desk research activity resulted mostly in a consequence of two important preceding desk 
research findings. First, as of March 2021, 'the list of all members' EURADON, which is the union of radon spas located in the EU, contained only one spa from the Czech Republic and one spa from Poland, on top of twelve spas from German speaking EU member states (nine spas from Germany and three spas from Austria). Second, the glossary of English language terms available at the website of European Spas Association (ESPA) contains an entry for the term 'radon' (defined for their purposes as "analgetic and anti-inflammatory inert gas used to treat illnesses like Morbus Bechterew and rheumatoid arthritis"), but not for the term "radon spa(s)' or any other relevant term using the word 'radon'. Given the above outlined reasons, we have decided to identify spas relevant for our pilot desk research activity (whose results are presented in this paper) by ourselves, in particular by a method based on searching the internet using the 'Google' search engine, with using different combinations of the terms 'radon', 'spa', 'radon spa', 'radon treatment' and 'radon medical treatment'. As a method of a verification of our desk research results presented in section 3.1, we verified existence of such descriptions of spa services in English sections of spa website that were, in our opinion, are fully in line with a radon medical therapy as defined by Nagy, Kavasi, Kovacs and Somlai (2008). This means that we have applied a very specific method in order to identify relevant spas for our research (i.e. spas with English language texts used in marketing of radon medical therapy), which has not been aimed at a preparation of any complete list of radon spas. Instead, we have aimed to obtain only the partial results (section 3.1), whose further analysis (section 3.2) has been a core of our method applied in order to identify the challenges dealt with in section 4 . In sections 3.1 and 3.3, we are explicit about a very probable existence of additional radon spas in the 'non German speaking members of the EU', and the reasons why the methods described in this section could not lead to their identification/verification.

\section{Results}

This section summarizes the results of our own desk research activities whose methods are presented in section 2 .

\subsection{Identification and selection of internet pages with English language texts marketing radon therapies at spas in non-German speaking EU countries}

Using the method described in section 2, we identified seven different spas in the EU, but outside of Austria and Germany (i.e. in non German speaking EU member states). They are presented in Table 1. 
With regard these research results, it needs to be stressed that they do not compose a complete list of 'radon spas' in non German speaking countries of the EU. Instead, Table 1 presents only a list of such websites of a spa facility or a spa town (in the non German speaking countries of the EU) whose English language parts/mutations contained description of radon medical therapies in line with the radon medical therapy definition dealt with in sections 1 and 2. This means that our research results presented in this section do not contain spas that market radon spas therapies in any other than English language. As was explained above, the reasons of limiting our desk research activity to English language texts relate to the specifics of, and internal agreements within our research project with the acronym RadoNorm, dealt with in section 2. The results of our desk research that might help to indicate additional spas providing radon medical therapies are dealt with in section 3.3 .

Table 1 Identified spas / spa facilities in non-German speaking EU member states (with a radon therapy) whose 'English parts of webpages' have been included in our pilot desk research

\begin{tabular}{|c|c|c|c|}
\hline $\begin{array}{c}\text { Name of spa } \\
\text { municipality/resort) }\end{array}$ & Country & $\begin{array}{l}\text { Owner of a website } \\
\text { (spa town/facility) }\end{array}$ & $\begin{array}{l}\text { Link to English part of a } \\
\text { chosen spa town / spa } \\
\text { facility website }\end{array}$ \\
\hline $\begin{array}{c}\text { Narechenski Bani } \\
\text { (Narechen Baths) }\end{array}$ & Bulgaria & $\begin{array}{l}\text { BalneoComplex } \\
\text { 'Medica-Narechen' }\end{array}$ & medicanarechen.bg/en/ \\
\hline Pavel Banya & Bulgaria & $\begin{array}{l}\text { Rehabilitation clinic } \\
\text { "Dr. Gechevi" }\end{array}$ & gechevi.bg/?lang=en \\
\hline Jáchymov & $\begin{array}{c}\text { Czech } \\
\text { Republic }\end{array}$ & $\begin{array}{l}\text { Léčebné lázně } \\
\text { Jáchymov a.s. (spa) }\end{array}$ & laznejachymov.cz/en/ \\
\hline $\begin{array}{l}\text { Therma (island } \\
\text { Ikaria) }\end{array}$ & Greece & $\begin{array}{l}\text { Appolon municipal } \\
\text { thermal Spa }\end{array}$ & $\begin{array}{c}\text { visitikaria.gr/en/discover/ther } \\
\text { mal-spas/appolon-spa }\end{array}$ \\
\hline $\begin{array}{l}\text { (Therme di) } \\
\text { Lurisia }\end{array}$ & Italy & $\begin{array}{l}\text { Istituto Idrotermale } \\
\text { di Lurisia (spa) }\end{array}$ & termedilurisia.it/en/ \\
\hline $\begin{array}{l}\text { Merano } \\
\text { (Meran) }\end{array}$ & Italy & Therme Merano (spa) & termemerano.it/en \\
\hline Świeradów-Zdrój & Poland & $\begin{array}{l}\text { Świeradów-Zdrój } \\
\text { (spa town) }\end{array}$ & swieradowzdroj.pl/en \\
\hline
\end{tabular}

Source: Own desk research (as described above and below).

\subsection{Internet marketing of radon therapies in English language by spas in non-German} speaking EU member states (preliminary pilot desk research results)

Due to the above outlined limits in the accreditation of research of the Faculty of Economic of the UMB, and the scope of the journal, our analysis of English language texts at the websites listed in Table 1 has been rather limited so far. For example, we have not conducted framing analysis with regard to radon medical therapies marketing at these identified websites. The reasons of this omission related ineligibility of interdisciplinarity with medical, natural and/or 
technical sciences in research accreditation of the Faculty of Economics of the UMB under the relevant Slovak laws.

We found English language texts at these seven internet pages differed significantly. For example, the English part of the Appolon spa website was rather minimalistic, which we have considered understandable given that this is a small municipal spa facility. On the contrary, we have found by far the most detailed English language explanations of radon medical therapies at the Jáchymov spa website. The two additional findings of our desk research perhaps explain this finding: this spa is considered the World's first radon spa (Zölzer et al., 2013), and it is a for profit business operated by a large spa holding.

At all the English language sections of spa facilities' websites listed in Table 1, we have been able to find the information referring to a requirement to either present a medical prescription, or have a prior appointment with the spa's own medical staff, i.e. in order for a spa client to be eligible for a balneotherapy and/or a radon medical therapy at a given spa. With regard to the Polish spa town Świeradów-Zdrój, we have found that the website of the main (and probably the only) spa facility at this spa town that advertised provision of a radon medical treatment, 'Uzdrowisko Świeradów-Czerniawa Sp.z.', did not have an English section. Apart from the Polish language, we found only German and Russian language sections of this spa facility's website. Using relevant English language terms and techniques in an internet search engine, we have found detailed information with regard to how an obligatory medical examination prior to a radon therapy is organised at this spa - in the English language, this information was presented at the website Sanatoriums.com (2021).

With five from six websites of spa facilities, we easily found information explaining the most common indications and contraindications with regard to radon medical therapy service(s) offered by these facilities. With regard to the only exception in this regard - the municipal spa Appolon - we were able to find this kind of information using relevant English language terms and techniques in an internet search engine at the website Visit Ikaria (2021). However, this website dedicated to marketing of a wide set of tourist services on the Greek island Ikaria, contained a detailed explanation of radon therapy not particularly for the Appolon spa, but at the same place also for some other spas at this tourist destination.

Given the above outlined reasons, we have decided not to search for and analyse such marketing texts at the English language parts of the seven websites listed in Table 1 that would fall at least partially under medical, natural and/or technical sciences. For the purposes related to planning of a primary research under the RadoNorm project, it is relevant that we have found usage of English language texts falling under medical, technical and/or natural sciences among 
internet marketing of all the six identified spas as well of the spa town Świeradów-Zdrój without any reference to an external source which could help readers uneducated in medical, technical and/or natural sciences to understand these marketing texts correctly. As relevant texts in this regard, we have considered for example texts presenting radon concentration values in bathing waters at given spa facilities and/or spa town, resp. at the Ikaria Island. We assume that in order for readers of English language texts about radon concentrations at the relevant radon spas' websites to understand radon concentration values correctly, it might be helpful that these parts of the spa websites would, for example, contain a link to English language text dealing with radon concentrations at radon spas. This would provide a more understandable measurement of radon concentration values which was the case of several websites whose English language content has been researched within the desk research activity whose results are presented in this article.

\subsection{Other relevant spas in non-German speaking countries of the EU}

Apart from Austria, Germany and the countries presented in the Table 1, Zdrojewicz and Strzelczyk (2006) refer also to France and Hungary among the European countries in which 'traditional spas with high radon concentration' have been constructed and operated. With regard to France, our search of English language academic sources resulted in finding only one Abstract, moreover more than sixty years old, in which Fritsch, Pinset and Coursaget (1958) mention radon doses of 21 day radon therapy cure at the La Bourboule spa. Using relevant techniques to search texts of this spa's webpage (www.grandsthermes-bourboule.com), we have been unable to find any English language texts, as well as any text in any other language containing the term 'radon'.

The part of our desk research composed of using relevant internet search engines, in which we added words 'Hungary' and/or 'Budapest' among the terms referred to in section 2, has not resulted in identifying any spa facility in Hungary/Budapest whose website would use English language texts to market availability/existence of radon medical therapy services. We have found and briefly reviewed few relevant academic texts, from which perhaps the most relevant data were published by Palotai, Mádl-Szőnyi and Horváth (2005). According to these quoted authors, with regard to spas in the Hungarian capital Budapest, the highest bathing waters' radon concentration measurements equalled “ $\sim 60 \mathrm{~Bq} / 1$ radon and $\sim 1000 \mathrm{mBq} / 1$ radium concentrations" in the Rudas spa's water. This has been, moreover, referred as "the highest in Hungary's ground waters". Given the above referred limitation of research accreditation and a scope of this paper, we have not attempted to analyse potential relevancy of these quoted 
findings for the purpose of this paper, as this would inevitably cross boundaries of SSH and involve considerations that fall under medical sciences. The preliminary finding of our pilot desk research suggests that Rudas spa or any other spa in Hungary does not use English language texts for marketing of radon therapy as defined by the quoted Hungarian authors Nagy, Kavasi, Kovacs and Somlai (2008).

As mentioned in the previous section, one of unintentional findings of our desk research concerned references to radon medical therapies related to the other spas at the Greek island Ikaria than the Appolon spa (presented in Table 1 and included in our desk research). Our additional desk research has resulted in finding that "along Ikaria's coastline there are several areas where radioenergic hot mineral springs flow into the sea from the shoreline where it is possible for one to bath \& swim. These springs are perfect for those seeking relaxation and milder forms of "unprescribed spa treatment" (Island-Ikaria.com, 2021a). According to the data presented at the webpage Visit Ikaria (2021), apart from the spring Apollo which (included in the Table 1), "strongly radioactive" are also the springs Mustafa, Kratsa and Artemis. The radon measurement results published by Danali Cotsaki and Margomenou-Leonidopoulou (1989) confirm this for the Artemis spring, but provide no data for the Mustafa and Kratsa springs. The quoted authors also published radon concentration data for the spa Asclepius (Asklipios), which is located in Agios Kirikos, operated by the municipality, but currently under ongoing renovations (Island-Ikaria.com, 2021b).

According to the data published by Danali Cotsaki and Margomenou-Leonidopoulou (1989), bathing waters at the former ancient natural thermal spas at Kamena Vourla (a seaside town) and Loutraki (a seaside resort about 80 kilometres from Athens) had much lower radon concentrations than the spring used by the Appolon spa at Therma/Ikaria (included in Table 1). We have been unable to obtain any more recent data/information related to these two spas.

According to the results of measurements conducted at selected spas located on the Greek island Lesbos, published by Vogiannis et al. (2004), radon concentration were below $100 \mathrm{~Bq} / \mathrm{L}$, with the exception of thermal waters used at the Eftalou spa (113-304 Bq/L) and the Polichnitos spa (126-202 Bq/L). As mentioned above, given a limitation of research accreditation and the scope of this paper, we have not attempted to interpret the above quoted data, as this would inevitably cross boundaries of SSH and involve considerations that fall under medical and/or natural sciences. We refer to this challenge in the forthcoming section 3.

\section{Discussion}


Taking into account our desk research results concerning both the relevant theoretical background (section 1) and the content of English language texts used for marketing of radon therapies at several different spas in the EU (section 3.2), we have identified three different groups of challenges for applied social science research of radon spas' marketing activities, which are discussed in sections 4.1 - 4.3. In section 4.4, we take an important note concerning challenges that related to radon spas research related ethical issues.

\subsection{Challenges related to theoretical background}

Even in those EU member states where a clear delimitation of competences in spa services involving radon medical therapies have been approved, and relevant research accreditation laws allow an interdisciplinary research involving both SSH and medical science research, specific challenges arise in relation to the theoretical background (as outlined in section 1). For example, despite attempts to define boundaries between medical tourism, health tourism and wellness tourism under tourism sciences, this can be perceived by some academic experts as "impossible or undesirable" (Cook, 2008). We have found this as a potential challenge relevant for a research in a field of spa marketing because spa clients' motivations, quality perceptions etc., in particular when related to radon medical therapies, can hardly be linked with a typical component of motivation for tourism services referred/defined as "escapism from the everyday and routine'. On a contrary, taking the results of our pilot desk research of texts at the websites presented in Table 1 into account, we assume that important aspects of spa clients' motivations related to radon medical therapies may be linked to chronical illnesses and/or a chronic pain, i.e. research subjects falling dominantly, or even in full, under medical sciences.

As we have explained in section 1, we have not been able to found any explicit or implicit (indirect, negative) definition of the term 'radon spa(s)' within our desk research activities, despite a quite frequent use of this umbrella term in both academic and non-academic literature which we have studies. Given all the arguments presented in the relevant part of a theoretical overview (i.e. in section 1.2), use of any of the existing theoretical definitions of health, medical, wellness and/or spa tourism may be inappropriate particularly because the SSH research of radon spas should respect different legal, historical and cultural context in individual states with regard to medical therapies. This challenge is not new - on the contrary, for ex. Cook (2008) went even further in this regard, when he made a general statement, not in any way related to radon medical therapies at spas, according to which "a definition of tourism and more specifically, health and medical tourism, might be impossible or undesirable”. Despite this, however, it may be worthwhile noting that the term health tourism has been 
defined/understood/used by a majority of the authors (whose publications we have reviewed both within and outside our RadoNorm project incited desk research activity dealt with in this paper) as an umbrella term for several different 'specific tourisms' related to health, for ex. as an umbrella term for medical, spa and wellness tourism. Most of the authors explicitly stated that their definitions/understanding have been 'geographically limited' for specific single EU member states, respecting specific/unique context of the given state dealt with in their publications. Because many of these academic sources are not available in the English language, we do not quote them in this paper.

Moreover, as some of the spa products marketed at the websites presented in Table 1 implicitly suggest, positioning of radon medical therapies within spa tourism services may differ among individual spa clients significantly. Among other potential reasons, this relates to unclear boundaries with regard to these spas' marketing activities going beyond boundaries of the so called 'purely medical tourism' (i.e. tourism filled with medical services reimbursed by health insurance companies), i.e. falling under another type of tourism, such as the so called 'preventive tourism' (a part of health tourism), or even the so-called wellness tourism. In this regard, we have noted that the Jáchymov spa (2021a) advertises the product titled 'Spa trial', respectively 'Treatment on trial', which includes " $1 \mathrm{x}$ medical consultation, $3 \mathrm{x}$ radon bath" and seven different other medical/health spa treatment services. Inclusion of (only) three radon baths in this spa products makes radon therapy positioning challenging in the context presented by the Jáchymov spa (2021b) leaflet, according to which the curative range is 10 to 24 radon baths. Therefore, an attempt to position the above referred product 'Spa trial', respectively 'Treatment on trial' under 'purely medical tourism', respectively 'preventive tourism' inevitably involves challenges falling under medical science judgements about curative ranges of radon baths (i.e. going beyond SSH, moreover in a way which is clearly ineligible under the relevant Slovak laws dealt with in section 3.1). Similar challenges with regard to positioning of related spa services under health tourism may, for example, relate to research of 'radon-rich springs that flow into the sea' at the Ikaria island in Greece, and therefore provide a potential for 'milder forms of unprescribed spa treatment' (Island-Ikaria.com, 2021a).

\subsection{Challenges with regard to respecting research accreditation limits under the Slovak University Act}

The current Slovak Act. no. 131/2002 Coll. on Higher Education and on Amendments to Certain Acts, as amended (further referred as 'the Slovak University Act') does not allow existence of interdisciplinary research departments at the Slovak Universities accredited under 
SSH. Therefore, the current Slovak Laws inevitably cause specific challenges particularly with regard to research that is inevitably interdisciplinary.

For Universities focusing on SSH, these challenges exist regardless of the extent in which research interdisciplinarity under the Slovak Laws would concern natural, technical and/or medical sciences. However, given the nature, sensitivity, ethical aspects, responsibility of the State, etc., inevitably linked with research activities falling under medical sciences, the so called Slovak Accreditation Commission (the key legal body under the Slovak Laws in these regards) does not allow accreditation of research activities falling under medical sciences outside of the faculties of medicine. As explained in the paragraph above, this applies to an interdisciplinary research involving medical sciences and SSH as well.

Scientific research of marketing activities of pro-profit entities typically falls under economics, psychology, sociology and management disciplines, i.e. under the disciplines falling under SSH in full. Therefore, if a correct understanding of products marketed by pro-profit entities does not inevitably require any significant scientific judgment falling under technical, natural and/or medical sciences, research activities related to such products fall under $\mathrm{SSH}$ in full as well. Therefore, research accreditations granted to the Slovak faculties of Economics allow any cross-disciplinary research involving economics, psychology, sociology and management disciplines, as long as boundaries of SSH as set by the relevant Slovak Laws, norms, etc. are respected in full.

However, when pro-profit entities in tourism provide (also) medical services, both theoretical framework and research accreditation inevitably involves relationships between tourism and health. Therefore, spa marketing inevitably includes marketing of special tourism products in interdisciplinary research fields of medical tourism and/or health tourism, resp. also travel medicine, etc. As we have explained in section 1, boundaries of these interdisciplinary disciplines may be defined by different academic authors in tourism sciences "conceptually completely inconsistently" (Kušen, 2011). Therefore, even without any relation to radon therapy, should research of spa marketing inevitably require any significant scientific judgment falling under technical, natural and/or medical sciences, it would most probably by ineligible under the above outlined content of the Slovak University Act.

In the above outlined specific Slovak legal context and theoretical background, research of spas' medical products involving radon medical therapy may be extremely challenging. On a top of all the above outlined reasons, it needs to be emphasized that provision of radon medical therapies goes beyond typical delimitation of competences in tourism services (Ibid.), because apart from national health sector and tourism sector authorities, it may inevitably involve also 
[ionizing/radioactive] radiation protection authorities/departments/offices. In this context, challenges with regard to accreditation of University research may be the most difficult in these EU member states where the relevant Laws do not specify delimitation of competences in spa services involving radon medical therapies.

\subsection{Lacking relevant academic publications in SSH}

One of our desk research findings concerned the popularity of health/medical tourism and marketing related research activities falling under SSH (section 1.3). However, as we have emphasized in section 1.4, a very thorough desk research activity, conducted within the RadoNorm project (referred in the Acknowledgment section), resulted in finding only one author of academic papers dealing with radon medical therapies whose research falls under SSH. Moreover, this author's research activities concerned almost dominantly with radon medical therapies at 'health mines' in Montana (USA), and not radon therapies at spas. This author explained that radon medical therapy remained "a non-sanctioned treatment eagerly sought by certain patients, but scorned or dismissed by many physicians" in the USA (Erickson, 2007c).

Even moreover, the most relevant book for our research written and independently self-published by Liechti (2020), titled 'Radon Spas and Health Mines: Worldwide Review of Radon Therapy', does not fall under SSH. Even if, in a very hypothetical case which may most probably not happen, this book would be peer-reviewed and 're-published' by any academic publisher, it would largely fall under technical sciences, and moreover under citizen science. The reason is that, despite that the quoted author dedicated a small part of his focus on marketing practices of spas directly related and fully focused on radon medical therapies, a core part of his field research concerned radon concentrations measurements using two different devices of the same kind and type.

\subsection{Ethical issues related challenges}

Some of the results of our desk research, in particular those presented in sections 1.2 and 4.1, concerned unclear boundaries between 'spa tourism' and 'medical tourism'. In this regard, it needs to be stressed that some of our desk research findings implicitly indicated that motivation to use radon medical services at spas may often be linked to chronical illnesses and/or a chronical pain of spa patients/clients. This may result in specific challenges with regard to the ethics of research, especially should filed research of spa patients suffering chronical pain would involve covert research methods, for ex. non-participatory observations. Respect not 
only to specific national level laws and policies, but also to a local historical and cultural context, may be crucial in this regard. Given that we have not identified a single spa in Slovakia marketing radon medical therapy, we have not performed any desk research focused on ethical issues of radon spas related research activities

\section{Conclusion}

Using the method described in section 2, we have identified only seven such spa facilities/towns in the EU member states outside of Austria and Germany whose websites advertise radon medical therapies in the English language (Table 1 in section 3.1). However, the additional results of our desk research, summarise in section 3.3, may be helpful in identification of additional spas in the EU member states outside of Austria and Germany that provide radon medical therapy, but do not advertise this in English.

One of the most important findings of our desk research concerns the differences among individual spa facilities in relation to how the English parts/mutations of their websites advertise and explain the context, nature and benefits of radon medical therapies. Despite these differences, all the spa websites contained also English language information referring to a requirement to either present a medical prescription, or have a prior appointment with the spa's own medical staff in order to be eligible for balneotherapy and/or a radon medical therapy at a given spa. At the same time, we have not found a single website which would link/direct its English language readers into a website of any external authority/institution/subject that would provide any official information about radon medical therapy legal status, indications and contraindications, relevant medical research results, etc. This may be a very relevant finding not only to the RadoNorm project research team, but also to other stakeholders interested in a medical radon therapy.

In the Discussion section, we outlined four different groups of challenges which we prepared based on the summary of a relevant theoretical background (section 1) and the relevant pilot desk research preliminary results (section 3). While one group of these challenges directly concern only the UMB staff under the Slovak Laws (section 4.2), it may be potentially relevant to interested researchers in foreign countries as well, in case if relevant national legislations imposes any limits to interdisciplinarity of research, especially those relevant for SSH and medical sciences. The other groups of challenges (sections 4.1, 4.3 and 4.4) may quite probably be relevant also to researchers outside of Slovakia, relevant stakeholders and/or anyone interested in radon spas' related research falling under SSH. 
Given the above outlined international context, and a lack of relevant publications falling under SSH (section 4.3), in order to overcome the above outlined four different groups of challenges, a maximal transparency may be beneficial. Therefore, despite having only preliminary results of a pilot research, we have decided to publish them in a form of this open access article.

Acknowledgement: The research results presented in this paper benefited from discussions and preliminary results in the context of the action/project entitled 'Towards effective radiation protection based on improved scientific evidence and social considerations - focus on radon and NORM' (acronymed 'RadoNorm') which has received funding from the Euratom research and training programme 2019-2020 under grant agreement No 900009”. More information about the RadoNorm project can be found at the project website https://www.radonorm.eu/.

\section{References}

[1] Armstrong, G., Kotler, P., Trifts, V. \& Buchwitz, L.A. (2017). Marketing: an introduction (Sixth Canadian edition). Toronto, CA: Pearson.

[2] Becker, K. (2004). One century of radon therapy. International Journal of Low Radiation, 1(3), 334-357. doi: 10.1504/IJLR.2004.005434.

[3] Cook, P. S. (2008). What is health and medical tourism? The annual conference of the Australian Sociological Association, 2 to 5 December 2008. Melbourne (Victoria): The University of Melbourne. Retrieved from: https://www.academia.edu/278439/What_is_Health_and_Medical_Tourism (last accessed 2021-03-15).

[4] Danali-Cotsaki, S. \& Margomenou-Leonidopoulou, G. (1989). Natural radioactivity of the Greek spas in Ikaria, Kamena Vourla and Loutraki. (Report no. DEMO 89/20; IAEA ref. no. 28029924). Athens, GR: National Research Centre for the Physical Sciences Democritos. Retrieved from: https://www.osti.gov/etdeweb/servlets/purl/454918 (last accessed 2021-03-16).

[5] Davis, J. B. \& Jovanovic, F. (2021). Economics' Boundaries with Other Sciences and within Itself. Journal of the History of Economic Thought, (forthcoming). Preprint at SocArXiv. https://osf.io/nh96u (last accessed 2021-03-15).

[6] Erickson, B. E. (2007a). Radioactive pain relief: health care strategies and risk assessment among elderly persons with arthritis at radon health mines. The Journal of Alternative and Complementary Medicine, 13(3), 375-379. doi: 10.1089/acm.2006.6213. 
[7] Erickson, B. E. (2007b). The Therapeutic use of Radon: A Biomedical Treatment in Europe; An "Alternative" Remedy in the United States. Dose-Response, 5(1), 48-62. doi: 10.2203/dose-response.06-007.Erickson.

[8] Erickson, B. E. (2007c). Toxin or medicine? Explanatory models of radon in Montana health mines. Medical Anthropology Quarterly, 21(1), 1-21. doi: 10.1525/maq.2007.21.1.1.

[9] Fleur, S., Azara, I. \& Michopoulou, E. (2018). Local community attitudes and perceptions towards thermalism. International Journal of Spa and Wellness, 1(1), 55-68. doi: $10.1080 / 24721735.2018 .1432451$.

[10] Fritsch, A., Pinset, I. \& Coursaget, J. (1958). Study of the radioactive content of water and gases from thermal sources at La Bourboule, Le Mont-Dore and Royat (in French). Abstract in English. Retrieved from: https://www.osti.gov/biblio/4236988-study$\underline{\text { radioactive-content-water-gases-from-thermal-sources-la-bourboule-le-mont-dore-royat }}$ (last accessed 2021-03-15).

[11] International spa association. (2021). Spa-goers / Definition of a spa / Types of spas. Retrieved from: https://experienceispa.com/resources/spa-goers (last accessed 2021-0312).

[12] Island-Ikaria.com (2021a). Ikaria Mineral Springs \& Thermal Spas. Retrieved from: http://www.island-ikaria.com/activities/Spas-Therapy (last accessed 2021-03-12).

[13] Island-Ikaria.com (2021b). Asklipios Spring-Spa - Therma, Ikaria. http://www.islandikaria.com/activities/Asklipios-Spring (last accessed 2021-03-17).

[14]Jafari J. \& Xiao H. (eds). (2016). Encyclopedia of Tourism. Cham, DE: Springer. doi: 10.1007/978-3-319-01384-8.

[15] Jáchymov spa. (2021a). Spa tasting. Retrieved from: https://www.laznejachymov.cz/en/treatment-on-trial/ (last accessed 2021-03-22).

[16] Jáchymov spa. (2021b). Radon is Energy - Energy is life [leaflet]. Retrieved from: http://www.laznejachymov.cz/Public/Files/prospekty/2018/en/LLJ-Radon.pdf ～(last accessed 2021-03-22).

[17] Kessel, F., Rosenfield, P. \& Anderson, N.B. (2008). Interdisciplinary Research: Case Studies from Health and Social Science. New York, NY: Oxford University Press. doi: 10.1093/acprof:oso/9780195324273.001.0001.

[18] Kušen, E. (2011). Positioning medical tourism in the broader framework of health tourism. Tourism : an international interdisciplinary journal 59(1), 95-99. ISSN 1332-7461. 
[19]Large, D. C. (2015). The grand spas of Central Europe: a history of intrigue, politics, art, and healing. Lanham, MD: Rowman \& Littlefield.

[20]Lettner, H. et al. (2017). Radon in the exhaled air of patients in radon therapy. Radiation Protection Dosimetry, 177(1-2), 78-82. doi: 10.1093/rpd/ncx153.

[21]Letunovska, N., Kwilinski, A., \& Kaminska, B. (2020). Scientific Research in The Health Tourism Market: A Systematic Literature Review. Health Economics and Management Review, 1(1), 8-19. doi: 10.21272/hem.2020.1-01.

[22]Liechti, D. (2020). Radon Spas and Health Mines: Worldwide Review of Radon Therapy. Independently Published.

[23]Lindgreen, A., Di Benedetto, C. A., Brodie, R. J. \& van der Borgh, M. (2020). [Editorial] How to undertake great cross-disciplinary research. Industrial Marketing Management,90, A1-A5. doi: 10.1016/j.indmarman.2020.03.025.

[24] Mueller, H. \& Kaufmann, E. (2001). Wellness tourism: Market analysis of a special health tourism segment and implications for the hotel industry. Journal of Vacation Marketing, 7(1), 5-17. doi: 10.1177/135676670100700101.

[25] Nagy, K., Kavasi, N., Kovacs, T. \& Somlai, J. (2008). Radon Therapy and Speleotherapy in Hungary. Press Therm Climat, 145 (2008), 219-225.

[26]Palotai, M., Mádl-Szőnyi, J. \& Horváth, Á. (2005). A Budapest Gellért- és a József-hegy felszín alatti vizeiben mért radon- és rádiumtartalom lehetséges forrásai [Potential radon and radium sources for subsurface water of Gellért and József Hills, Budapest, Hungary]. $\begin{array}{llll}\text { Általános } & \text { Földtani } & \text { Szemle } & \text { 29(1), }\end{array}$ https://www.researchgate.net/publication/237650127_Potential_radon_and_radium_sourc es_for_subsurface_water_of_Gellert_and_Jozsef_Hills_Budapest_Hungary (last accessed 2021-03-15).

[27]Peris-Ortiz, M. and Álvarez-García, J. (eds.) (2015). Health and Wellness Tourism: Emergence of a New Market Segment. New York, NY: Springer Publishing. doi: 10.1007/978-3-319-11490.

[28]Ramos V. \& Untong A. (2016). Spa tourism. In J. Jafari J., \& H. Xiao (eds) Encyclopedia of Tourism. Cham, DE: Springer. doi: 10.1007/978-3-319-01384-8_185

[29]Rhoten, D. \& Parker, A. (2004). Education: Risks and Rewards of an Interdisciplinary Research Path. Science, 306(5704), 2046. doi: 10.1126/science.1103628.

[30] Routh, H. B., Bhowmik, K. R., Parish, L. C. \& Witkowski, J. A. (1996). Balneology, mineral water, and spas in historical perspective. Clinics in Dermatology, 14(6), 551-554. doi: 10.1016/S0738-081X(96)00083-1. 
[31] Sanatoriums.com. (2021). Retrieved from: https://www.sanatoriums.com/en/swieradowzdroj/treatment (last accessed 2021-03-17).

[32] SpaDreams.

(2021).

Radon

treatment.

Retrieved

from:

https://www.spadreams.com/healing-holidays/healing-therapies/radon-treatment/ (last accessed 2021-03-17).

[33] Tomkiv, Y. et al. (2021). Collection of existing methods, databases, scales, protocols and other tools - state of the art. Draft Deliverable 6.1.1 [of the RadoNorm project] (internal document of the RadoNorm project team). Retrieved from: https://www.radonorm.eu/publications/deliverables/.

[34] van Tubergen, A. \& van der Linden, S. (2002). A brief history of spa therapy. Annals of the rheumatic diseases. 61(3), 273-5. doi: 10.1136/ard.61.3.273.

[35] Visit Ikaria (2021). Hot springs. Retrieved from: http://www.visitikaria.gr/en/ikaria/hotsprings\#.YE-QFnvPxPb (last accessed 2021-03-15).

[36] Vogiannis, E., Nikolopoulos, D., Louizi, A. \& Halvadakis, C. (2004). Radon variations during treatment in thermal spas of Lesvos Island (Greece). Journal of environmental radioactivity, 76(3), 283-94. doi:10.1016/j.jenvrad.2003.11.009.

[37]Zdrojewicz, Z., \& Strzelczyk, J. (2006). Radon Treatment Controversy. Dose-Response 4(2), 106-118. doi: 10.2203/dose-response.05-025.Zdrojewicz.

[38]Zölzer, F. et al. (2013). Micronuclei in lymphocytes from radon spa personnel in the Czech Republic. International Archives of Occupational and Environmental Health, 86(6), 629633. doi: 10.1007/s00420-012-0795-z.

Authors' addresses: Ing. Peter Mihók, PhD. Matej Bel University in Banská Bystrica, Faculty of Economics, Tajovského 10, 97590 Banská Bystrica, Slovakia, e-mail: peter.mihok@umb.sk 